\title{
School absenteeism during menstruation among adolescent girls in resettlement colonies of Delhi: a community-based cross-sectional study
} Suneela Garg ${ }^{1}$, Mongjam Meghachandra Singh ${ }^{2}$, Yamini Marimuthu ${ }^{3}$, Amod Borle ${ }^{4}$, Nidhi Bhatnagar ${ }^{5}$, Saurav Basu 6

${ }^{1}$ Director Professor, Dept. of Community Medicine, Maulana Azad Medical College, New Delhi; ${ }^{2}$ Director Professor, Dept. of Community Medicine, Maulana Azad Medical College, New Delhi; ${ }^{3}$ Assistant Professor, Dept. of Community Medicine, ESIC Medical College and Post Graduate Institute of Medical Sciences and Research, Rajajinagar, Bengaluru-560010; ${ }^{4}$ Assistant Professor, Dept. of Community Medicine, Maulana Azad Medical College, New Delhi; ${ }^{5}$ Assistant Professor, Dept. of Community Medicine, Maulana Azad Medical College, New Delhi; ${ }^{6}$ Senior Resident, Dept. of Community Medicine, Maulana Azad Medical College, New Delhi

\begin{tabular}{|l|l|l|l|l|l|l|l|}
\hline Abstract & Introduction & Methodology & Results & Conclusion & References & Citation & Tables / Figures \\
\hline
\end{tabular}

\section{Corresponding Author}

Dr Yamini Marimuthu, Assistant Professor, Dept. of Community Medicine, ESIC Medical College and Post Graduate Institute of Medical Sciences and Research, Rajajinagar, Bengaluru-560010 E Mail ID: yaminivaishnavidevi@gmail.com

\section{Citation}

Garg S, Singh MM, Marimuthu Y, Borle A, Bhatnagar N, Basu S. School absenteeism during menstruation among adolescent girls in resettlement colonies of Delhi: a community-based cross-sectional study. Indian J Comm Health. 2021;33(1):82-89. https://doi.org/10.47203/IJCH.2021.v33i01.011

Source of Funding: National Health Mission, Delhi Conflict of Interest: None declared

\section{Article Cycle}

Received: 01/12/2020; Revision: 13/01/2021; Accepted: 14/02/2021; Published: 31/03/2021

This work is licensed under a Creative Commons Attribution 4.0 International License.

\section{Abstract}

Background: School absenteeism during menstruation and its related effects are preventable through identification of factors associated with it and implementation of region specific appropriate public health measures. Objectives: To assess the prevalence of school absenteeism during menstruation and its associated factors among adolescent girls residing in the resettlement colonies of Delhi. Methods: A community-based crosssectional study was conducted in the urban resettlement colonies of Delhi during 2019 in which 712 school going adolescent girls were interviewed. The details about school absenteeism, its perceived reasons, various sociodemographic details, menstrual hygiene practices were assessed using pretested semi structured questionnaire. The data were entered in MS Excel and analysed using STATA statistical software version 14. Results: The prevalence of school absenteeism during menstruation among adolescent girls of resettlement colony was 43.1\%(95\% Cl:39.5 - 46.7). Out of 307 girls who had school absenteeism, 285(92.8\%) had missed for 1-3days. The most common self-reported reasons for school absenteeism during menstruation were pain during menstruation (75.6\%) followed by staining of cloths(43.6\%) and uncomfortable feeling(39.4\%). Studying in government school ( $\mathrm{PR}=1.4,95 \% \mathrm{Cl}: 1.1-2.0$ ), suffering from menstruation-related problems (aPR=1.9, 95\% $\mathrm{Cl}: 1.5-2.4$ ) and pads being provided from schools(PR=1.3, 95\% Cl:1.1-1.7) were significantly associated with school absenteeism. Conclusions: Almost half of the adolescent girls in resettlement colonies had school absenteeism. The characteristics like government school, pads being provided from school, menstruation related problems like weakness, irritation, perceived weight gain and breast pain was significantly associated with school absenteeism. The factors associated with school absenteeism needs to be addressed with appropriate public health interventions. 


\section{Keywords}

Adolescent Health; Menstrual Hygiene; Menstruation; Prevalence; School Absenteeism.

\section{Introduction}

As highlighted by the sustainable development goals education for all and gender equity, girls education is very crucial for country's development since educated women have better health and better maintain healthy family.(1) Attending schools regularly help the girls to attain their full potential. However, higher rates of school dropout persists especially in secondary level education particularly for adolescent girls.(2)

Even though menstruation is a normal phenomenon, it is considered as a barrier for education of girls in low and middle income countries due to inadequate hygiene facilities, myths and misconceptions associated with menstruation.(3) Cultural taboos and religious restriction during menstruation restrains the girls from leaving the houses during menstruation. $(4,5)$ Studies have reported that menstrual hygiene practices affects the school absenteeism during menstruation.(6,7) Menstrual hygiene practices in turn is affected by the sanitation facilities available at schools like lack of adequate privacy, sanitary facilities with water availability, lack of cleanliness, waste disposal facilities. $(8,9)$ Menstruation related problems like pain during menstruation, increased bleeding also leads to school absenteeism. $(10,11)$

An Ethiopian study observed that more than half of the adolescent girls reported to be absent from school.(12) A Bangladeshi study reported that $41 \%$ of the girls had school absenteeism.(6) It is reported that $43 \%$ of the girls in rural Pune remain absent for schools during menstruation.(7) Another study in Delhi also reported that $40 \%$ of the girls had school absenteeism. However in resettlement colonies of Delhi the school absenteeism during menstruation might not be the same for the following reasons. First, the resettlement colonies are occupied by people who were living in slums of Delhi. Second, they are still outside the ambit of "planned colonies" and provision of basic services like sanitation and health facilities is being done in a phased manner.(13) Third, the people living in resettlement colonies belong to low socio-economic status, low literacy rate. School absenteeism during menstruation and its related effects are preventable through identification of factors associated with it and implementation of region specific appropriate public health measures.

\section{Aims \& Objectives}

1. To assess the prevalence of school absenteeism during menstruation among the adolescent girls residing in resettlement colonies of Delhi.

2. To determine the factors associated with school absenteeism during menstruation among the adolescent girls residing in resettlement colonies of Delhi

\section{Material \& Methods}

Study type: Community-based cross-sectional study Study area: This study was conducted in the resettlement colonies of Delhi. The resettlement colonies constitute relocated urban slums, dense, unplanned neighbourhoods with inadequate sanitation and hygiene availability. A large proportion of the residents in resettlement colonies belong to lower-middle socioeconomic classes.

Study duration and population: This study was conducted for 12 months from March 2019 to February 2020 among adolescent girls (11-19 years) residing in the randomly selected resettlement colonies in urban and rural areas of Delhi. Adolescent girls who were currently going to schools were included. Adolescent girls with serious illness and those who are not willing to participate in the study were excluded from the study. Any physical or mental illness due to which the participants were not able to provide reliable answers to the questionnaire was considered as serious illness.

Sample size calculation and sampling technique: Considering the expected prevalence of satisfactory frequency of changing sanitary napkins from a previous study as $12.7 \%$, with $20 \%$ relative precision and $5 \%$ alpha error, the sample size was calculation to be 681 using OpenEpi, Version 3.(14) To adjust for the effect of clustering in resettlement colonies, a design effect of 1.5 was used to inflate the sample size to 1022 . The sample size was then rounded to 1130 to increase power.

Multi stage sampling technique was used for selection of the study areas and participants. Since 97.5\% of the Delhi population live in urban areas and $2.5 \%$ in rural areas; we recruited 1100 participants from urban population and 30 from rural population. In Delhi, out of 11 districts, four districts were 
randomly selected which were East, North East, South and North West districts. Subsequently, resettlement colonies were selected in each district. The selected urban resettlement colonies were Gokalpuri in North East, Sunlight colony and Sarai Kale Khan in South, Mangolpuri in North West and Kalyanpuri in East district. The number of blocks in each resettlement colonies was obtained and the blocks were selected using population proportionate to size technique. The number of households in each block was enumerated. Sampling interval was calculated by dividing the total number of houses by the number of participants required to be enrolled from each block. A random start determined by selecting a random number in the first sampling interval. From the random start the sampling interval was added subsequently to select the subsequent households. The adolescents in the selected household were recruited in the study. If there were more than one adolescent in the household one adolescent was selected using KISH selection grid.

Study Procedure: After obtaining informed written consent from eligible adolescents, data were collected using a pretested semi structured interview schedule. Details like socio-demographic details, menstrual hygiene practices and school absenteeism, reasons for school absenteeism during menstruation were collected.

\section{Operational definitions:}

1. School absenteeism during menstruation: Being absent for school during the last menstruation at least single day is considered as school absenteeism.

2. Proper disposal of pads: Wrapping of the used napkin and throwing in dustbin or incineration or burning is considered as proper disposal of pads.

3. Improper disposal of pads: Other methods of disposal of used sanitary napkins like throwing it in open or throwing it in dustbin without wrapping or flushing in toilet are considered as improper disposal.

Variables: Age of the adolescents was categorized as early (10-14 years) and late adolescents (15-19 years) based on the UNICEF classification (15). Socioeconomic status of the study participants were classified based on Modified BG Prasad Scale 2019 based on the per capita income of the family.(16)

Statistical analysis: Data were entered in MS Excel and analysed using STATA statistical software version 14 (StataCorp LCC, Lakeway Drive College Station, Texas, USA).(17) Continuous variables were summarized as mean with standard deviation (SD) or median with interquartile range (IQR) based on the distribution of data. Categorical variables were summarized as frequencies and proportions. Chi square test or Fischer's exact test was used to assess the statistical significance of the association between two categorical variables. The association between the various characteristics and school absenteeism during menstruation was assessed using bivariate logistic regression and expressed as prevalence ratio (PR) with 95\% confidence interval. The multivariate analysis was done using generalized linear model with Poisson family and log link function and expressed as adjusted prevalence ratio (aPR) with $95 \%$ confidence interval. The characteristics with $p$ value less than 0.20 in the bivariate logistic regression was included in the multivariate models. The characteristics included in the model were age, type of school, type of absorbent materials used, provision of sanitary napkins in schools and menstruation related problems. A $p$ value less than 0.05 was considered significant.

Ethical considerations: Ethical clearance certificate was obtained from the Institutional Ethical Committee (IEC) of Maulana Azad Medical College (MAMC). Data was collected after getting informed written consent from the study participants. After collecting the details, the adolescents were given health education regarding the healthy menstrual hygiene management and government schemes related to the menstrual hygiene.

\section{Results}

Out of 1130 girls included in the study, 712 girls were currently going to school. None of the school going adolescent girls was married and $31.7 \%$ of them were early adolescents (10-14 years) and $77 \%$ of them were educated above 9th standard [Table 1]. Approximately $90 \%$ were studying in government schools. Around $88 \%$ of the study populations were exclusively using sanitary pads with $94.8 \%$ doing proper disposal of used pads [Table 2]. The frequency of changing pads is less than two per day for all the school going adolescent girls. The prevalence of school absenteeism during menstruation among adolescent girls of resettlement colony was $43.1 \%$ ( $95 \% \mathrm{Cl}$ : $39.5-46.7$ ). Out of 307 girls who had school absenteeism, 285 (92.8\%) had missed only for 1 -3days and 22 (7.2\%) have missed for $\geq 4$ days. The most common selfreported reasons for school absenteeism during 
menstruation were pain during menstruation (75.6\%) followed by staining of cloths $(43.6 \%)$ uncomfortable feeling (39.4\%), afraid of others making fun of me (13.7\%) [Table 3].

The socio-demographic characteristics like age, education, religion, socioeconomic status, residential area were not significantly associated with school absenteeism [Table 4]. Girls studying in government school had $40 \%$ increased prevalence ( $\mathrm{PR}=1.4,95 \% \mathrm{Cl}: 1.1-2.0)$ of school absenteeism as compared to the girls who are studying in private schools and the association was statistically significant ( $p$ value $=0.015$ ).

The menstrual hygiene practices like type of absorbent material used, frequency of changing pads and disposal of used pads were also not significantly associated with school absenteeism. The prevalence of school absenteeism was significantly higher in girls with menstruation related problems (aPR=1.9, 95\% $\mathrm{Cl}$ : 1.5-2.4). Among the menstruation related problems, breast pain ( $\mathrm{PR}=1.6,95 \% \mathrm{Cl}: 1.3-2.1)$, perceived weight gain ( $\mathrm{PR}=1.495 \% \mathrm{Cl}$ : 1.1-1.9), weakness ( $\mathrm{PR}=1.395 \% \mathrm{Cl}: 1.1-1.6)$ and irritation ( $P R=1.395 \% \mathrm{Cl}: 1.1-1.5)$ during menstruation was significantly associated with school absenteeism.

\section{Discussion}

Avoidable school absenteeism due to social and public health factors among adolescent girls is a major concern related to gender justice, especially in developing world settings. School absenteeism is well-established to negatively impact learning and educational outcomes in lower and middle-income countries. In this study, nearly $43 \%$ of adolescent girls reporting missing school at least for one day during their menstrual period.

In the present study, the most common reason for missing school among girls was pain during menstruation and the girls having menstruation related problems were nearly twice more likely to miss school compared to those without such problems. Previous studies have also attributed dysmenorrhea to be the most important contributor to school absenteeism. $(6,7,18)$ Moreover, sociodemographic characteristics like low socioeconomic status that were previously reported as risk factors for missing school especially during menstruation were not associated with school absenteeism in the present study. This finding suggests that the provision of pad distribution by the government promotes equitable reproductive health.
Nevertheless, in this study, we observed girls staining of clothes during menstruation as a potential reason for missing school. Previous studies have also reported that lack of awareness contributing to girls not changing their pads at schools. $(9,19)$ In this study, the lack of supply of pads by the school did not contribute to school absenteeism. The adequacy of quantity and quantity of pads being provided in Udaan scheme needs to be assessed.

The lack of sanitation facilities in schools for girls may also inhibit their urge to change their menstrual pads at schools. A systematic review reported only $56 \%$ of schools in India had the facility of a separate toilet for girls.(19) Nevertheless, in the present study, most schools had adequate sanitation facilities (running water, soap and toilets) reflecting increased preparedness of school in this regard as per the mandate of the landmark Swacch Bharat Mission. Very few girls in this study also reported the lack of privacy in schools as a reason for not changing pads. These findings suggest that educational interventions towards improving the awareness of girls and sensitizing them towards the necessity of changing pads during menstruation even at schoolsettings warrant prioritization.

A disconcerting finding of the present study was that among girls reporting school absenteeism, a significant proportion (6.1\%) attributed it to their apprehensions over being teased at school. Previously, the teasing of menstruating girls by male teachers and their male classmates has been reported due to misconceptions, cultural taboos and patriarchal notions of menstruations. (20) All such activities may contribute to loss of self-esteem among girls. Health education needs to be done for male children and teachers to prevent this.

Strengths of the study are external validity of the study is good since probability sampling technique is used and appropriate statistical analysis is done to assess the association of various factors with school absenteeism.

\section{Conclusion}

The present study found that $43 \%$ of the adolescent girls in resettlement colonies had school absenteeism. The characteristics like government school, pads being provided from school, menstruation related problems like weakness, irritation, perceived weight gain and breast pain was significantly associated with school absenteeism. 


\section{Recommendation}

The perceived menstruation related problems needs to be addressed with counselling services to prevent school absenteeism. The reasons for increased school absenteeism during menstruation in government schools need to be identified preferably through qualitative studies and addressed.

\section{Limitation of the study}

The study is done only among adolescent girls in resettlement colonies so the extrapolation of the results to other adolescent girls needs to be done with caution. The availability of safe and nonpolluting method of waste pad disposal within schools which might be a factor for school absenteeism is not studied in the study.

\section{Relevance of the study}

The resettlement colonies are occupied by people who were living in slums of Delhi. People living in resettlement colonies belong to low socio-economic status and low literacy rate. The current study adds evidence about the school absenteeism and its associated factors among adolescent girls in the resettlement colonies of Delhi.

\section{Authors Contribution}

SG and MMS were involved with concept, design and conduct of the study. YM and NB were involved with the conduct study, literature search, data analysis and preparation of manuscript. YM, SB and NB were involved in discussion and drafting the manuscript. $A B$ was involved with concept and design of the study, literature search, data analysis and revising the manuscript Critical revision and final approval was done by all the contributors. SG will act as guarantor.

\section{Acknowledgement}

We acknowledge the National Health Mission, Delhi for the support.

\section{References}

1. World Bank Group. Education Global Practice: Smarter Education Systems for Brighter Futures. 2016. Available from:

http://documents.worldbank.org/curated/en/2123414 67999691082/pdf/98450-REVISED-PUBLIC-WB-EGPReaching-Girls-040816-final6-web.pdf [Accessed on 15 Feb 2021]

2. Patton GC, Sawyer SM, Santelli JS, Ross DA, Afifi R, Allen $N B$, et al. Our future: a Lancet commission on adolescent health and wellbeing. Lancet. 2016;387(10036):242378. Available from:
https://www.thelancet.com/journals/lancet/article/PIIS 0140-6736(16)00579-1/fulltext

3. Sommer M, Caruso BA, Sahin M, Calderon T, Cavill S, Mahon T, et al. A Time for Global Action: Addressing Girls' Menstrual Hygiene Management Needs in Schools. PLOS Med. 2016;13(2):e1001962. Available from: http://dx.plos.org/10.1371/journal.pmed.1001962

4. Garg S, Anand T. Menstruation related myths in India: strategies for combating it. J Family Med Prim Care. 2015;4(2):184-6. doi: 10.4103/2249-4863.154627. PMID: 25949964; PMCID: PMC4408698.[PubMed].

5. van Eijk AM, Sivakami M, Thakkar MB, Bauman A, Laserson KF, Coates S, Phillips-Howard PA. Menstrual hygiene management among adolescent girls in India: a systematic review and meta-analysis. BMJ Open. 2016;6(3):e010290. doi: 10.1136/bmjopen-2015010290. PMID: 26936906; PMCID: PMC4785312.[PubMed]

6. Alam MU, Luby SP, Halder AK, Islam K, Opel A, Shoab AK, Ghosh PK, Rahman M, Mahon T, Unicomb L. Menstrual hygiene management among Bangladeshi adolescent schoolgirls and risk factors affecting school absence: results from a cross- sectional survey. BMJ Open. 2017;7(7):e015508. doi: 10.1136/bmjopen-2016015508. PMID: 28694347; PMCID: PMC5541609.[PubMed]

7. Vashisht A, Pathak R, Agarwalla R, Patavegar BN, Panda $M$. School absenteeism during menstruation amongst adolescent girls in Delhi, India. J Family Community Med. 2018;25(3):163-168. doi: 10.4103/jfcm.JFCM_161_17. PMID: 30220845; PMCID: PMC6130156.[PubMed]

8. Sharma S, Mehra D, Brusselaers N, Mehra S. Menstrual Hygiene Preparedness Among Schools in India: A Systematic Review and Meta-Analysis of System-and Policy-Level Actions. Int J Environ Res Public Health. 2020;17(2):647. doi: 10.3390/ijerph17020647. PMID: 31963862; PMCID: PMC7013590.[PubMed]

9. Sivakami M, Maria van Eijk A, Thakur $\mathrm{H}$, Kakade N, Patil C, Shinde S, Surani N, Bauman A, Zulaika G, Kabir Y, Dobhal A, Singh P, Tahiliani B, Mason L, Alexander KT, Thakkar MB, Laserson KF, Phillips-Howard PA. Effect of menstruation on girls and their schooling, and facilitators of menstrual hygiene management in schools: surveys in government schools in three states in India, 2015. J Glob Health. 2019;9(1):010408. doi: 10.7189/jogh.09.010408. PMID: 30546869; PMCID: PMC6286883. [PubMed].

10. Lghoul S, Loukid M, Hilali MK. Prevalence and predictors of dysmenorrhea among a population of adolescent's schoolgirls (Morocco). Saudi J Biol Sci. 2020;27(7):17371742. doi: 10.1016/j.sjbs.2020.05.022. Epub 2020 May 20. PMID: 32565690; PMCID: PMC7296472.[PubMed]

11. Nesreen AA S, Ahmed E A, Hamada A Abd El W, Ashraf S F, Gaber K H. Epidemiology of Dysmenorrhea among University Students in Egypt. Int J Women's Heal Wellness. 2018;4(1).

12. Belay S, Kuhlmann AKS, Wall LL. Girls' attendance at school after a menstrual hygiene intervention in northern Ethiopia. Int J Gynaecol Obstet. 
2020;149(3):287-291. doi: 10.1002/ijgo.13127. Epub 2020 Mar 15. PMID: 32083719.[PubMed].

13. Categorisation of settlement of Delhi. 2015. Available from:

https://www.cprindia.org/sites/default/files/policybriefs/Categorisation-of-Settlement-in-Delhi.pdf [Accessed on $11 \mathrm{feb}$ 2021]

14. Goel P, Kumar R, Meena G, Garg S. Association of sociodemographic characteristics with KAP regarding menstrual hygiene among women in an urban area in Delhi. Trop J Obstet Gynaecol. 2018;35(2):158.

15. UNICEF. Early and Late Adolescence. Available from: https://www.unicef.org/sowc2011/pdfs/Early-and-lateadolescence.pdf [Accessed on 09 feb 2020]

16. Pandey VK, Aggarwal P, Kakkar R. Modified BG Prasad Socio-economic Classification, Update -2019. Indian J Community Health. 2019;31(1):123-5. Available from: https://www.iapsmupuk.org/journal/index.php/IJCH/ar ticle/view/1055/906

\section{7}

. StataCorp. Stata Statistical Software: Release 14. College Station, TX, USA: StataCorp LP; 2017.

18. Ranabhat D, Nepal S, Regmi B. Menstrual Hygiene Practice and School Absenteeism among Rural Adolescent girls of Kalikot district. Nepal Med Coll J. 2019;21(4):258-64.

19. Ganguly L, Satpati L. Sanitation and hygiene status among school students: A micro study on some selective schools of North Dumdum municipality area, West Bengal. Int Res J Public Environ Heal [Internet]. 2019;6(6):127-31. Available from: https://journalissues.org/wpcontent/uploads/2019/09/Ganguly-and-Satpati.pdf

20. Benshaul-Tolonen A, Aguilar-Gomez S, Heller Batzer N, Cai R, Nyanza EC. Period teasing, stigma and knowledge: A survey of adolescent boys and girls in Northern Tanzania. PLoS One. 2020;15(10):e0239914. doi: 10.1371/journal.pone.0239914. PMID: 33112868; PMCID: PMC7592731.[PubMed].

\section{Tables}

TABLE 1 ASSOCIATION OF SOCIO-DEMOGRAPHIC CHARACTERISTICS WITH SCHOOL ABSENTEEISM AMONG THE SCHOOL GOING ADOLESCENT GIRLS IN RESETTLEMENT COLONIES OF DELHI, N=712

\begin{tabular}{|c|c|c|c|c|c|}
\hline Characteristics & $\begin{array}{l}\text { Total } \\
\mathrm{N}=712 \\
\text { Frequency (\%) }\end{array}$ & $\begin{array}{l}\text { School absenteeism } \\
\text { present }(n=307) \\
\text { Frequency }(\%)^{\dagger}\end{array}$ & PR $(95 \% \mathrm{Cl})$ & aPR $(95 \% \mathrm{Cl})$ & $\begin{array}{l}\text { p- } \\
\text { value } \neq\end{array}$ \\
\hline \multicolumn{6}{|c|}{ 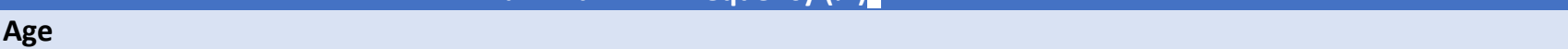 } \\
\hline Early adolescents (10-14 years) & $226(31.7)$ & $87(38.5)$ & 1 & 1 & 0.089 \\
\hline Late adolescents (15-19 years) & $486(68.3)$ & $220(45.3)$ & $1.2(0.9-1.4)$ & $1.1(0.9-1.3)$ & \\
\hline \multicolumn{6}{|l|}{ Education } \\
\hline Up to $8^{\text {th }}$ standard & $164(23.0)$ & $74(45.1)$ & $1.1(0.9-1.3)$ & - & 0.555 \\
\hline $9^{\text {th }}$ standard and above & $548(77.0)$ & $233(42.5)$ & 1 & & \\
\hline \multicolumn{6}{|l|}{ Religion } \\
\hline Hindu & $612(85.9)$ & $269(43.9)$ & $1.1(0.8-1.5)$ & - & 0.265 \\
\hline Others(Muslim, Christian, Sikh) & $100(14.1)$ & $38(38.0)$ & 1 & & \\
\hline \multicolumn{6}{|l|}{ Type of family } \\
\hline Joint family & $111(15.6)$ & $45(40.5)$ & 1 & - & 0.551 \\
\hline Nuclear family & $601(84.4)$ & $262(43.5)$ & $1.0(0.8-1.4)$ & & \\
\hline \multicolumn{6}{|c|}{ Socioeconomic status (monthly per capita income)* } \\
\hline Class 1 (7008 and above) & $34(4.7)$ & $15(44.1)$ & 1 & - & 0.539 \\
\hline Class 2 (3504-7007) & $93(13.1)$ & $40(13.0)$ & $0.9(0.6-1.5)$ & & \\
\hline Class 3 (2102-3503) & $149(20.9)$ & 55 (17.9) & $0.8(0.5-1.2)$ & & \\
\hline Class $41051-2101$ & $241(33.9)$ & $109(45.2)$ & $1.0(0.6-1.5)$ & & \\
\hline Class 51050 and below & $195(27.4)$ & $88(45.1)$ & $1.0(0.6-1.5)$ & & \\
\hline \multicolumn{6}{|l|}{ Residential area } \\
\hline Urban & $695(97.6)$ & $300(43.1)$ & $1.04(0.5-1.8)$ & - & 0.870 \\
\hline Rural & $17(2.4)$ & $7(41.2)$ & 1 & & \\
\hline \multicolumn{6}{|l|}{ Type of School } \\
\hline Government school & $633(88.9)$ & $283(44.7)$ & $1.4(1.1-2.0)$ & $1.2(0.8-1.8)$ & 0.015 \\
\hline Private school & 79 (11.1) & $24(30.3)$ & 1 & 1 & \\
\hline $\begin{array}{l}\text { *Socioeconomic status classified } \\
\text { †The percentages mentioned in } \\
\text { ₹ The } p \text { value is for the crude PR }\end{array}$ & $\begin{array}{l}\text { using modified B } \\
\text { is column are } r c\end{array}$ & $\begin{array}{l}\text { Prasad Scale } 2019 . \\
\text { N percentages for each }\end{array}$ & & & \\
\hline
\end{tabular}


TABLE 2 ASSOCIATION OF MENSTRUATION-RELATED CHARACTERISTICS WITH SCHOOL ABSENTEEISM AMONG SCHOOL GOING ADOLESCENT GIRLS IN RESETTLEMENT COLONIES OF DELHI, $\mathbf{N}=712$

\begin{tabular}{|c|c|c|c|c|c|}
\hline Characteristics & $\begin{array}{l}\text { Total } \mathrm{N}=712 \\
\text { Frequency (\%) }\end{array}$ & $\begin{array}{l}\text { School absenteeism } \\
\text { present } n=307 \\
\text { Frequency }(\%) \dagger\end{array}$ & PR $(95 \% \mathrm{CI})$ & aPR $(95 \% \mathrm{Cl})$ & p-value $\ddagger$ \\
\hline \multicolumn{6}{|l|}{ Type of absorbent material } \\
\hline Exclusively using sanitary pads & $632(88.7)$ & $266(42.1)$ & 1 & 1 & 0.119 \\
\hline Cloth materials & $80(11.3)$ & $41(51.2)$ & $1.2(0.9-1.5)$ & $1.1(0.9-1.4)$ & \\
\hline \multicolumn{6}{|c|}{ Frequency of changing absorbent materials } \\
\hline$\leq 2$ times per day & $712(100)$ & $307(43.1)$ & - & - & - \\
\hline$\geq 3$ times per day & 0 & 0 & & & \\
\hline \multicolumn{6}{|l|}{ Disposal of pads } \\
\hline Proper & $675(94.8)$ & $289(42.8)$ & 1 & - & 0.485 \\
\hline Improper & $37(5.2)$ & $18(48.6)$ & $1.1(0.8-1.6)$ & & \\
\hline \multicolumn{6}{|l|}{ Water supply in school toilets } \\
\hline Continuous & $688(96.6)$ & $296(43.0)$ & $1.1(0.6-1.6)$ & - & 0.785 \\
\hline Intermittent & $24(3.4)$ & $11(45.8)$ & 1 & & \\
\hline \multicolumn{6}{|l|}{ Pads being provided from school } \\
\hline Yes & $591(83.0)$ & $267(45.2)$ & $1.3(1.1-1.7)$ & $1.2(0.9-1.6)$ & 0.014 \\
\hline No & $121(16.9)$ & $40(33.1)$ & 1 & 1 & \\
\hline \multicolumn{6}{|l|}{ Menstruation related problems } \\
\hline Present & $472(66.2)$ & $244(51.7)$ & $1.9(1.5-2.4)$ & $1.9(1.5-2.4)$ & $<0.001$ \\
\hline Absent & $240(33.7)$ & $63(26.3)$ & 1 & 1 & \\
\hline
\end{tabular}

TABLE 3 SELF-REPORTED REASONS FOR SCHOOL ABSENTEEISM DURING MENSTRUATION AMONG ADOLESCENT GIRLS OF RESETTLEMENT COLONIES, $\mathrm{N}=307 *$

\begin{tabular}{|l|l|}
\hline Pain during menstruation & $232(75.6)$ \\
\hline Staining of cloths & $134(43.6)$ \\
\hline Feeling uncomfortable & $121(39.4)$ \\
\hline Afraid of others making fun of me & $42(13.7)$ \\
\hline No privacy in school & $9(2.9)$ \\
\hline No place to dispose pads in schools & $8(2.6)$ \\
\hline *Multiple responses & \\
\hline
\end{tabular}

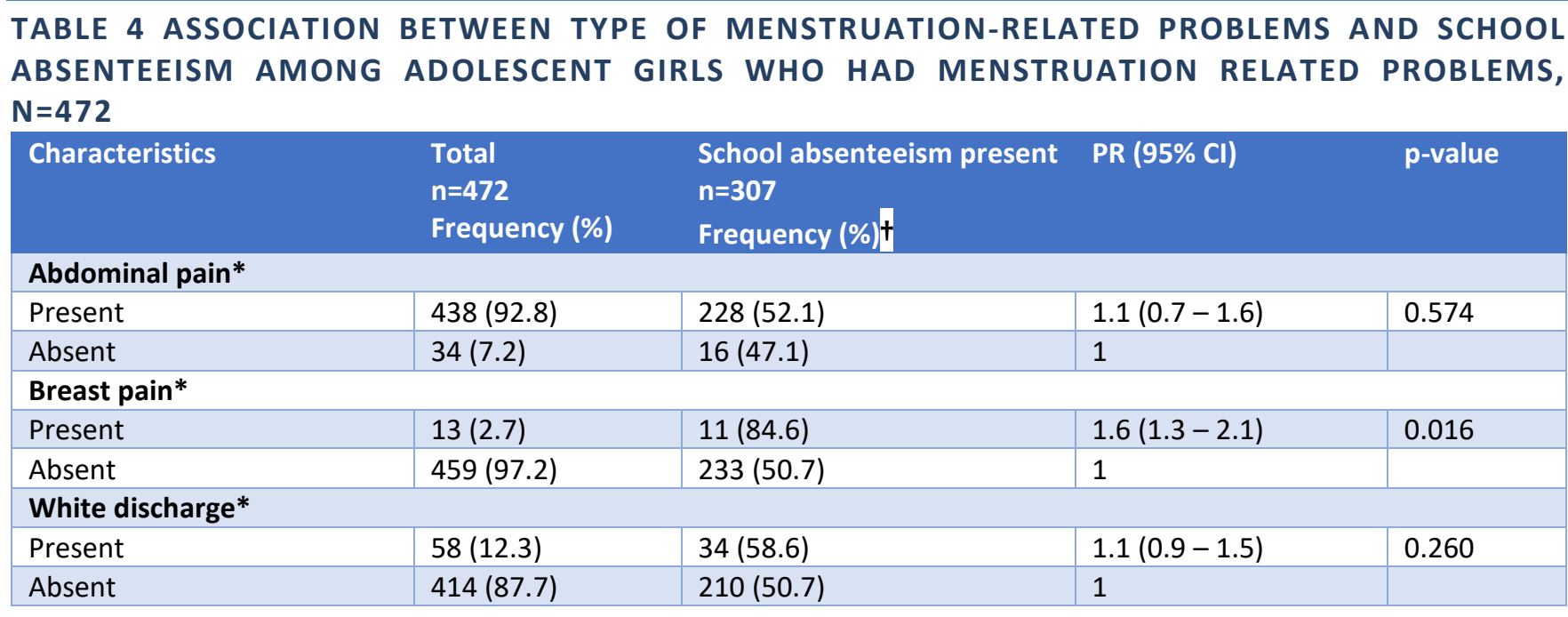




\begin{tabular}{|c|c|c|c|c|}
\hline Characteristics & $\begin{array}{l}\text { Total } \\
n=472 \\
\text { Frequency (\%) }\end{array}$ & $\begin{array}{l}\text { School absenteeism present } \\
n=307 \\
\text { Frequency }(\%) \dagger\end{array}$ & PR (95\% Cl) & p-value \\
\hline \multicolumn{5}{|c|}{ Bloating sensation* } \\
\hline Present & $11(2.3)$ & $7(63.6)$ & $1.2(0.7-1.9)$ & 0.423 \\
\hline Absent & $461(97.6)$ & $237(51.4)$ & 1 & \\
\hline \multicolumn{5}{|l|}{ Feeling low* } \\
\hline Present & $64(13.6)$ & $36(56.2)$ & $1.1(0.8-1.4)$ & 0.433 \\
\hline Absent & $408(86.4)$ & 208 (50.9) & 1 & \\
\hline \multicolumn{5}{|l|}{ Weight gain* } \\
\hline Present & $16(3.4)$ & $12(75)$ & $1.4(1.1-1.9)$ & 0.057 \\
\hline Absent & $456(96.6)$ & $232(50.8)$ & 1 & \\
\hline \multicolumn{5}{|l|}{ Weakness* } \\
\hline Present & 141 (29.9) & $89(63.1)$ & $1.3(1.1-1.6)$ & 0.001 \\
\hline Absent & 331 (70.1) & $155(46.8)$ & 1 & \\
\hline \multicolumn{5}{|l|}{ Irritation* } \\
\hline Present & $102(21.6)$ & $63(61.7)$ & $1.3(1.1-1.5)$ & 0.022 \\
\hline Absent & $370(78.3)$ & 181 (48.9) & 1 & \\
\hline \multicolumn{5}{|l|}{ Anxiety* } \\
\hline Present & $32(6.8)$ & $19(59.4)$ & $1.2(0.8-1.6)$ & 0.368 \\
\hline Absent & $440(93.2)$ & $225(51.7)$ & 1 & \\
\hline
\end{tabular}

